\title{
Corela
}

Cognition, représentation, langage

9-2 | 2011

Vol. $9, \mathrm{n}^{\circ} 2$

\section{Kissing goodbye}

\section{Isabelle Haïk}

\section{OpenEdition}

\section{Journals}

\section{Édition électronique}

URL : http://journals.openedition.org/corela/2314

DOI : 10.4000/corela.2314

ISSN : 1638-573X

\section{Éditeur}

Cercle linguistique du Centre et de l'Ouest - CerLICO

\section{Référence électronique}

Isabelle Haïk, «Kissing goodbye », Corela [En ligne], 9-2 | 2011, mis en ligne le 12 décembre 2011, consulté le 01 mai 2019. URL : http://journals.openedition.org/corela/2314 ; DOI : 10.4000/ corela.2314

Ce document a été généré automatiquement le 1 mai 2019.

\section{(c) (i) (2)(2)}

Corela - cognition, représentation, langage est mis à disposition selon les termes de la licence Creative Commons Attribution - Pas d'Utilisation Commerciale - Partage dans les Mêmes Conditions 4.0 International. 


\title{
Kissing goodbye
}

\author{
Isabelle Haïk
}

\section{Introduction}

1 There exists a construction in English, kiss goodbye, which has interesting properties. ${ }^{1}$ One of the interests of this construction is that it should shed light on the family of resultative constructions, if it is right, as claimed here, that it is an instance of it. This article is in three main parts, in the first section, it describes the properties of the construction. In the second, it lays out an analysis of resultative constructions that will be used in the third section. And in the third section it explains how the properties of the construction derive from it being a resultative construction which also has the form and meaning of a double object structure.

\section{Kiss goodbye}

\subsection{Description}

Let us consider the following sentence:

(1) The boy kissed his mother goodbye.

This sentence has the character of resultative constructions, like wipe the table clean, because it is interpreted as a blend of two propositions in one. One of the main interests of the kiss goodbye construction is the surprising property that the direct object of the main verb is also understood as an indirect object, as if, in this particular case, grammar allowed a violation of the theta-criterion, which normally rejects arguments that receive a theta-role twice. ${ }^{2}$ In (1), his mother is understood as the object of kiss and as the addressee of the saying goodbye by the boy, so, his mother seems to have both the DO function of kiss and the IO function of kissgoodbye. Note that the IO quality of this DP is evidenced by the prepositional frame with to:

(2) Kiss goodbye to freedom/ to brief encounters/to Irak, etc. 
4 Moreover, following researchers on resultatives, like Levin and Rapoport (1988), Levin and Rappaport Hovav (1999) and (2005), Talmy (1991), Mc Intyre (2004), Harley (2005) and Mateu (2001), as in all other cases of conflation, the $\mathrm{V}$ expresses a manner in which the embedded process is done. It is the case in this construction, which requires the interpretation that the kissing be done as a way of saying goodbye. I will expand on this later.

Let us consider in turn the restrictions on the three main elements of the construction, the two nominals and the verb.

\subsection{Constraints on the $\mathrm{N}$}

\subsubsection{Interjections}

The kiss goodbye construction is possible with expressions of salutations, like goodbye or so long, etc. or wishes, like good luck, as shown in (3). However, other expressions of wish like luck, a good life, a good meeting, etc., may not enter the construction, as shown in (4): ${ }^{3}$

(3) He kissed her goodbye/so long/good morning/ good night/goodbye/farewell/

bon voyage/hello/hi/good luck/.

(4) *He kissed her luck/a good life/a good meeting.

7 The difference between goodbye, so long or goodluck on the one hand and luck, a good life, a good meeting on the other, is that the first may be interjected ("Goodbye!", "Good night!", "Good luck!"), whereas the second may not (*uLuck!”, *u(A) good life!”, “*A good meeting!"). This shows that the nominal of the kiss goodbye construction is an interjection. Let us now turn to the nature of that interjection.

8 The interjections that cannot enter the construction are non-words, like psst, ouch, oups, etc. (the primary interjections of Ameka 1992a), or vulgar, slang or blasphemous exclamations which are expressions of feelings, like fuck, shit, my goodness, God, etc. (secondary interjections in Ameka 1992a):

(5) *He nudged her ouch/fuck/goodness/God/damn/shit, etc.

9 Insults, like "stupid!" or curses or expressions of disapproval like "shame on you" are rare in the kiss goodbye construction. We return to them in section 3.8. As for kiss somebody thanks, it has an unclear status, some speakers accept it, some do not. ${ }^{4}$

10 To conclude, the interjections that work best are formulae (Ameka 1992a and b), namely, interjections used through convention, that is to say, expected to be uttered in a certain given situation, in order to express something to the hearer. Analyzing interjections along the lines of Wierzbicka (1992), Ameka defines formulaic words as having a dictum, namely, a propositional content expressing the speaker's feeling, for example, that $\mathrm{s} / \mathrm{he}$ acknowledges the other with good morning, that s/he recognizes some fault with sorry, etc.

11 Let us look at two additional cases, welcome and goodluck. Considering welcome, for speakers who accept it, we may suppose that, even though it is less ritual than good morning because it is not expected to be uttered, it is nevertheless conventionally uttered in a specific situation, that of greeting. That allows it to be treated like goodmorning: ${ }^{5}$

(6) ?She kissed him welcome.

12 Now, consider good luck. It is not a formula and we hardly imagine a parent teaching their kid to go and say good luck to their aunt. This is because it is not uttered in a ritual. However, it is acceptable in that construction, so there must be some convention in it. 
Most of the phrases exchanged upon leaving are wishes, either goodbye, the distortion of the blessing God be with ye, or true wishes, like good luck, or have a good trip, a good vacation, etc. So, even if the phrases good luck, have a good trip, etc. are not conventional, the act of wishing that accompanies their utterance is, because it signals departure, which is enough for the kiss goodbye construction.

13 Let us now consider one other property of the interjections that enter the kissgoodbye construction, the requirement that they must licence an addressee. Ameka (1992b) has found an important distinctive property among interjections: certain may license an addressee without the need of a verb, and others do not:

(7) Merry Christmas/thanks/cheers/good morning/hello/hi/ to you!

(8) *Sorry/help to you.

14 The dative argument is the addressee of the speech act performed by the utterance of the interjection. Interestingly, all the interjections that may enter the kiss goodbye construction license an addressee. We will see in section 1.4 that the presence of the addressee is a necessary condition on this construction:

(9) Good morning/goodbye/good luck/thanks/hi, etc. to you.

15 However, note that some formulae take an addressee, as in (10), but they do not easily enter the kissgoodbye construction, as shown in (11):

(10) merry Christmas/happy birthday/welcome to you

(11) ??kiss somebody merry Christmas/happy birthday/welcome ${ }^{6}$

16 This means that the condition on the addressee is a necessary but not sufficient condition.

\subsubsection{Delocution}

17 Following Benveniste (1966), goodbye, goodluck, good night and others are, in say goodbye, say good night, etc., delocutive expressions, namely, interjections entering into a grammatical category either as the base of a new word or as a noun in a phrase. According to Benveniste, when a delocutive expression is integrated into a verb or a verb phrase, the verbal form containing it gets the metonymical meaning of 'do what uttering the interjection does'. Benveniste has analyzed the verb remercier 'thank' as a delocutive verb, coming from the interjection "merci" 'thank you' as its base, yielding the meaning 'do what saying "merci” does', namely 'show gratitude'. De Cornulier (1976) has pointed to morphological evidence that the verb remercier does not directly come from the delocution of "merci", but rather, from "merci" converted into a noun through a process of auto-delocution, whereby it names an utterance of the interjection, as is done in "mille mercis" 'a thousand thanks.' Then, when such a word is used delocutively, the verbal expression or the noun alone may name the act of doing what its utterance performs. ${ }^{7}$ Following Austin's (1962) theory of speech acts, a grammatical phrase saying that some interjection is uttered (like say $X, \operatorname{cry} X$, bid $X$, etc.) is an expression that names a speech act, the illocutionary act performed when one utters the interjection. An illocutionary act is an act that is done in uttering some particular expression. Saying "merci"performs,by way of convention, the illocutionary act of showing gratitude, and the verb remercier names this illocutionary act.

Observe that the verb, for instance, remercier or thank, does not necessarily have the literal meaning, "say "thanks"' ('utter "thanks"), the metonymy involved is such that delocutive expressions do not necessarily refer to an effective utterance of the 
interjection. This is not a necessary feature of delocution but it often happens. It is the same with the kiss goodbye construction, in which the interjection goodbye means that the referent of the subject says goodbye, that is to say, does the illocutionary act that is performed when uttering "goodbye", namely, signals departure, with or without an actual utterance of the interjection.

As far as I can see, the nouns that can be found in the kiss goodbye construction may all be used in a delocutive fashion with verbs of utterance, such as say,bid or wish:

(12)a. Say thanks/sorry/hi/hello/goodbye/good night/cheers etc. ${ }^{8}$

(12)b. Bid somebody welcome/goodbye.

(12)c. Wish somebody good luck.

This is not surprising, since the kiss goodbye construction uses delocution of the interjection. It is not excluded that some interjection(s) could be used in the kiss goodbye construction, and for some reason, could not be used with an utterance verb, but I have not found any.

21 So far, we have reached the following descriptive generalization of the kiss goodbye construction, to be accounted for in section 3.1:

(13) The kiss goodbye construction

In the V DP Interj construction, 1) Interj is a formula, 2) Verbing performs the act

that is performed when one utters the interjection.

\subsection{Constraints on the verb}

\subsubsection{Transitive and ditransitive verbs}

The following expressions are possible:

(14)a. He hugged her good night/good luck/good morning/thanks, etc

(14)b. He nudged her good night/good luck/good morning/thanks, etc.

(14)c. He patted her good night/good luck/good morning/thanks, etc.

(14)d. (?)He pinched her goodbye/good luck.

(14)e. Kick procrastination goodbye. (internet source)

They contrast with the following ill-formed sentences, which contain other transitive verbs, which could be used in an ironic or humorous fashion and would thus, to some extent, respect the manner condition expressed in (13), according to which the process named by the verb is a manner of performing the act performed in uttering the Interj:

(15)a. *The boss does not like her very much, he's going to fire her goodbye/thanks.

(15)b. * she wounded him goodbye.

(15)c. * She killed him goodbye/so long.

(15)d. *They hired him welcome.

(16) *He bored her goodbye/good night.

These show that only verbs of physical contact may enter the construction. Gruber (1970) and Jackendoff (1972) have shown that such verbs take Goal objects, rather than Themes. With verbs of contact with which the referent of the DO changes state, such as wound, the DO is a Theme. As shown by these authors, the locative nature of the Goal is evidenced by the prepositions which may be construed with the verb: hit (at) a target, the hitting at the target, but *the breaking in/at the vase, *the reading at/in the book. As for the role of the DO of psychological verbs like bore, they are Experiencers. Experiencer and Goal are particular instances of Location. Sometimes they are distinguished, sometimes not. For instance, in the English body-part construction, which Jackendoff (1990) and Massam 
(1989) show is limited to verbs of contact, only the physical Goal role participates in the construction:

(17)a. He hit her on the head.

(17)b. *He touched her on/in the heart.

Whereas these two roles are at some level undistinguished, yielding the metaphors of physical verbs into psychological expressions (cf. Bouchard 1995):

(18)a. John told her ${ }_{\text {Goal }}$ not to take the job.

(18)b. This told her ${ }_{\mathrm{Exp}}$ not to take the job.

In the kiss goodbye construction, from which psychological verbs are excluded, as shown in (16), fine-grained distinctions are at work and the DO cannot be an Experiencer.

As a last remark, concerning ditransitive verbs, the kiss goodbye construction cannot be formed on double object verbs, to which we come back in section 3.2, even if the meaning is compatible with the manner requirement of the construction:

(19) *He gave a kiss to her goodbye.

(20) *He blew a kiss to his hopes goodbye.

\subsubsection{Intransitive verbs}

29 According to me, the kiss goodbye construction with intransitive verbs, like smile, wave, wink, etc., is similar to fake object resultatives, in which complex-predicate formation is done in the syntax. As a conflated form, it must obey the congruence condition between the act named by the verb and the act performed by the utterance of the interjection, explaining why glare is better than look, because watching insistently may perform the act of a signal and not simply looking. Among them are included the widely used expressions with wave and smile:

(21) *she looked him goodbye.

(22) She glared him goodbye.

(23) He winked them goodbye.

(24) He waved me goodbye.

(25) He smiled me thanks. (Goldberg 1995, citing Rappaport and Levin1996)

According to Levin (1993), Levin and Rappaport Hovav (2005) and Massam (1990), the verbs wave and smile acquire the sense of verbs of creation, in which smiling creates the act of thanking and waving that of saluting. We can say that the gesture performs the act performed by the utterance of the interjection, which recalls the kiss goodbye construction. The same complex-predicate formation operates, but in the syntax. It may not be necessary to say that the verbs in question acquire the meaning of verbs of creation, because this derives from the manner condition on conflation. That condition requires that the verb name a conventional gesture that signals what the utterance of the interjection does, as with kiss goodbye. Formally, the structure obtained in syntax is that of a pure double object construction, slightly different from that in which the DP is the semantic direct object of the verb, as with the transitive kiss goodbye, which enters a mixed structure, as we will see. The two structures, kiss goodbye and wave goodbye, are compared in section 3.6.9

31 Lastly, poetic creations like the following, which often violate particular aspects of syntax or semantics, should not trouble us:

(26) I sit here by your side and weep you goodbye

(lyrics of "Portals of Light", Weinerhall Stefan, brought to my attention by

Dominique Legallois) 

argument which they must share - syntactically and semantically -, forcing the Goal DO of the verb to correspond to the addressee of the interjection. There are two cases to consider. First, the interjection does not take an argument, as in (27), and second, the verb and the interjection both take an argument, but do not both assign the same role, as in (28):

(27) *He nudged her stupid.

(28) *He raised his arm goodbye.

(27) is excluded because an insult like "stupid" does not take an addressee (*Stupid to you!) so the shared-argument requirement cannot be respected. As for (28), it is ruled out because his arm should but cannot be understood as the addressee of the interjection. Compare it with (29)-(30):10

(29) [...] he didn't pet my head good-bye.

(A Wolf at the Table, Augusten Burroughs, 2008, Island Roads)

(30) I reached out to shake his hand goodbye.

(Three Weeks to Say Goodbye, C. J. Box, 2008, St Martin's Press)

(28) describes a gesture involving a body-part, raise/wave one's arm, which does not name a contact, contrary to (29)-(30), in which the DO names the body-part of the individual which is touched and toward whom the gesture is done, and such sentences are fine. Broadly speaking then, the VPs of (29)-(30) involve a participant whose body-part is touched and who is the addressee of the interjection. This yields the following descriptive generalization, to be explained in section 3.1:

(31) Semantic condition on the kiss goodbye construction

The kiss goodbye construction is possible only if the DO of the V is a Goal and is the addressee of the formula. The Goal may be expressed by a body-part of the addressee.

The overall conclusion concerning the kinds of verbs that may enter the construction is that, for all speakers, the matrix verbs are verbs of contact, whose direct object is a Goal, necessarily corresponding to the addressee of the interjection. Then, for a number of speakers, and depending on the verb, the kiss goodbye construction is possible with some intransitives and excluded for all speakers with ditransitive verbs. We are thus entering the core of the syntax of the construction, and, in order to understand its properties, let us turn to resultative constructions. 


\section{Complex predicates}

\subsection{Complex predicates in resultative constructions} English and satellite-framed languages in general (Talmy 1991) grammaticalize the endpoint of events, a subject studied in Dowty (1979) and Tenny (1994); ${ }^{11}$ from Dowty (1979) for the claim that resultative constructions are complex predicates, worked out in the GB framework in Carrier and Randall (1992) and in the Minimalist framework in Winkler (1997); from Jayaseelan (1988) for the claim that when two predicates form a complex predicate, their theta-grids unite (in the mathematical sense of set-union); from Simpson (1983) and Hoekstra (1988) for the idea that resultatives somehow involve adding a Small Clause; from Williams (1994), Zubizarreta (1985) and Manzini (1983) for the claim that one mechanism, for instance reanalysis, may yield different results according to the domain in which the rule applies (lexicon or syntax); and from Higginbotham (1985) and Larson (1988) for the working of the links between lexical semantics and semantic saturation in the building of syntax. See also Boas (2003) and Ramchand (2008) for analyses of resultative constructions.

suggest a proposal using the idea that, in some types of complex-predicate formations, one argument is the argument of two heads at the same time. This idea has first been proposed by Baker (1989) and then in Baker and Stewart (1999) for serial constructions..$^{12}$ I will minimally differ from Baker and Stewart in stipulating that only the verb projects up, but the basic idea is the same.

In resultative constructions like wipe clean, clean does not fill an argument slot already present in the verbs's theta-grid but is added in it. This is different from the causative reanalysis rule in Romance or Japanese (Kayne 1977 and 1984, Manzini 1983, Zubizarreta 1985, Williams 1994, and Manning, Sag and Iida 1999) and from processes like nounincorporation (Baker 1988), compound-formation (Lieber 1983), affixation, and conversion (Kiparsky 1997), in which the incorporated material saturates an argument place of the verb. However, the syntactic and semantic device is similar to reanalysis in that the resulting predicate is like a single head, which may have one and only one subject, one and only one direct object, etc. Moreover, as in the discussion in Levin and Rappaport Hovav's work, for instance Levin and Rappaport Hovav (1999), it must name a single event (even if causation and succession of subevents are involved; Kratzer 2004). That event can be quantified and referred to, it takes place at one time and location, and it is introduced by the Davidsonian event place of the verb. The requirement that a complex verb name a single event explains the semantic restrictions that hold of complex predicates, as shown for instance in Levin and Rapoport's (1988) lexical subordination and current work on resultatives.

41

Our main task is to express the dual role of the complement in complex forms like wipe clean. Hoekstra (1988) has claimed that all conflation forms are produced by the addition of a Small Clause to a bare main verb. Differing slightly, because the verbal projection of the complex verb seems to be projected from the verb and not from the Adj, and because I want to keep a way to distinguish resultatives like wipe clean and fake-object resultatives like bark awake, let us state that Adj is not a projecting head in the complex verb, presumably a parameter of complex-predicate formation in general. 
42 Moreover, for Case-checking, we follow the usual assumptions based on Burzio's (1986) generalization revised by aspectual analyses such as Tenny's (1994), van Voorst's (1988) and Dowty's (1991), according to which a predicate may merge with v only if it has an argument (whether external, like Agent and Instrument, or internal, like Cause) that brings about the process that it denotes. ${ }^{13}$

43 Putting all these things together, consider the formation of the lexical resultative wipe clean. To explain the fact that lexical resultatives all have a shared argument, the basic idea is that lexical resultatives result from anchoring a predicate onto a verbal head. Not being the projecting head of the complex verb, that second predicate will have to find its argument(s) in the structure provided by the verb. The complex verb is an $\mathrm{X}^{\circ}$ form, which has clean as the first combining element with the verb wipe. When it enters the syntax, this complex verb merges with its arguments, and saturation takes place, respecting the Thematic Hierarchy, itself resulting from general principles yielding the order of the argument-places of the predicate. For simplicity, we will work on lexical representations with theta-roles, and we will not question how the relative ordering of the Thematic Hierarchy is arrived at.

(32) Lexical resultatives:

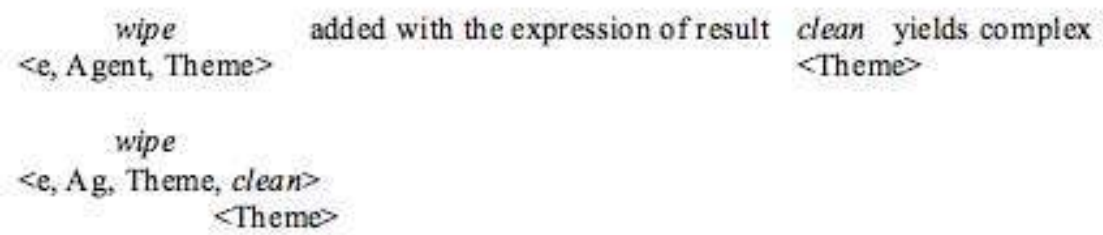

The lexical information on wipe <e, Ag, Theme, clean $>$ is that wipe has as endpoint the state named by clean applying to some argument, and that it names one event, involving two participants, an Agent and a Theme.

45 Such a lexical form undergoes the following syntactic derivation. First, the complex verb enters the syntax, as a bi-headed structure (the asterisk indicates that the place in the theta grid has been saturated):

(33)

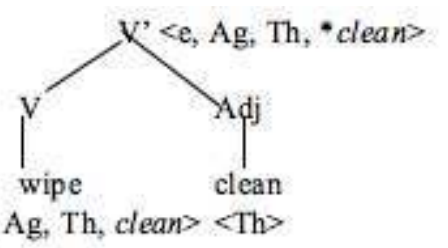

In a bi-headed structure, the two heads are syntactically and semantically active, meaning that they must see their argument-places saturated. Given the assumption that, in resultative constructions, $\mathrm{V}$ is the only projecting head, it projects up, so the $\mathrm{V}$ merges with the Theme DP, which saturates the Theme position of the V:

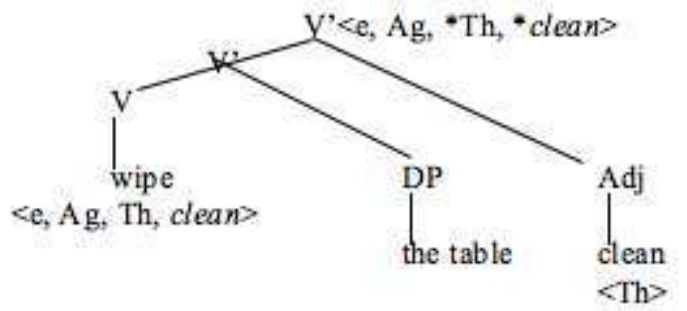


that clean is a predicate, Predication theory (Williams 1980, Stowell 1983, and Rothstein 1983 and later work) requires the Adj to have a subject. Following Gruber (1970), an adjective assigns a Theme role to its subject. Of the two argument places in the verb's grid, structurally and thematically, the only suitable one is the Theme. The Adj. anchors onto that structure, merging in the Spec-head relation with the available Theme argument. This yields:

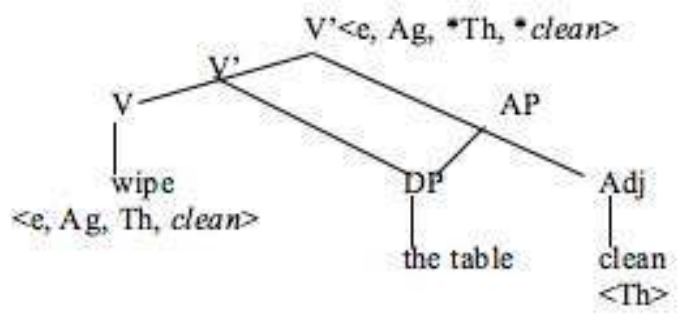

There are two unusual hypotheses in this proposal, first, multi-dominance over the converging DP node, and second, the fact that the derivation seems to violate compositionality conditions because the higher V' wipe + clean is constructed before its internal structure is. Concerning the converging node, it is a natural way to represent Jayaseelan's operation of union of theta-grids when the theta-grids of two predicates share an identical role. If one defines the theta-grid of the complex predicate wipeclean as the union of $<\mathrm{Ag}$, $\mathrm{Th}>\mathrm{and}<\mathrm{Th}>$, one gets wipe clean $<\mathrm{Ag}$, Th>, a complex verb with only one internal argument and two theta-active heads. In addition, even if he does not use the union operation, Baker (1989) has advanced this converging representation to account for object sharing in serial verb constructions, in which the DP is the DO of the first V and the specifier of the second verb. The reason I haven't used Jayaseelan's formalism in a stricter fashion is that I have aimed to derive the obligatory character of argument-sharing, rather than stipulating its necessity. ${ }^{14}$ Here, the sharing of the Theme argument derives from the necessity for a predicate to have a subject, and the hypothesis that the Adj is not a projecting head of the complex verb.

One possible criticism about the shared argument is that it looks like a violation of the theta-criterion, because the argument receives a theta-role twice. However, the restriction on the number of theta assigners aims at excluding movement into thetapositions. See Baker (1989) for a theoretical discussion. In this article, we keep the theta condition that arguments must receive one and only one theta-role, rendering argumentsharing possible, if the two heads assign the same role.

The second originality of the derivation in (35) has to do with rules of composition. Let us consider how it is possible to go downward in the building of a structure. Syntactic structure is binary compositional, and I assume that this is because syntax reflects the ordering of the various mental operations that take place when words and phrases are put together. In the derivation proposed above, the internal syntactic structure of the complex predicate is constructed after the complex predicate merges, which seems to be a problem. However, the verbal structure that has wipe and clean together is not produced in syntax. The verbal structure wipe clean results from the projection in syntax of the already computed complex verb. In other words, the merged structure given in (33) is the morphological construct that enters the syntax. There, in syntax, saturation may start at the head level, from bottom up. In that case, each head merges with its arguments in the usual compositional manner. 
51 Let us now complete the analysis. For ease of exposition, in (34)-(35), I have shown a stepwise merging of the complement DP, first with the V, then with the Adj, but in fact, respecting the notion of semantic unit, the converging-argument representation indicates that that argument is computed simultaneously with the two heads, meaning that the two branches related the DP with the two heads are formed simultaneously.

An alternative account of the structure of the kiss goodbye construction could be one in which kiss goodbye is a resultative complex predicate in a Larson-type representation, as in Winkler (1997), so it would start with the V kiss goodbye having the Goal as its argument, with raising of kiss to $\mathrm{v}$ and raising of the Goal to the inner subject position, as in either (36a) or (b): ${ }^{15}$

(36)
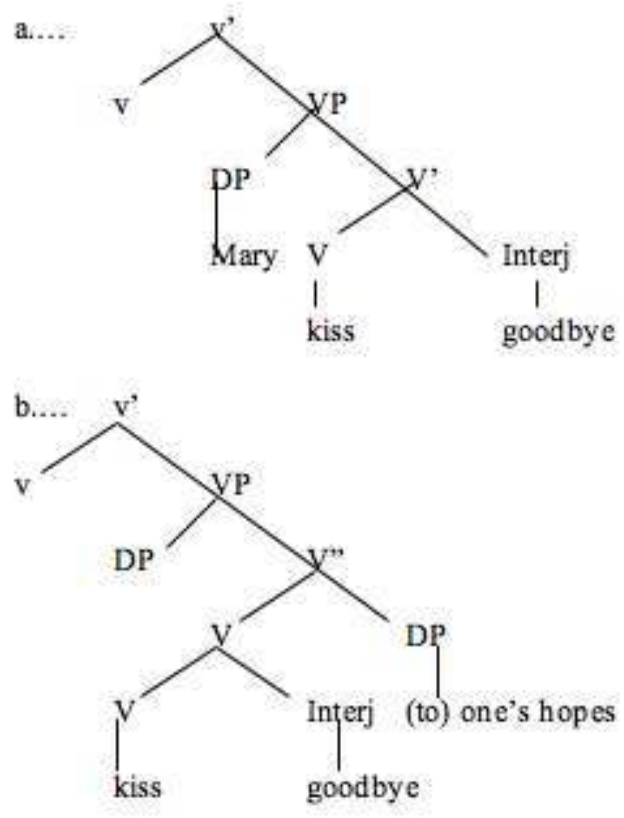

There is no technical problem with these analyses except that, in (36a), Mary should find a way to saturate the Goal place of goodbye. As for (36b), it represents kiss goodbye as a verbal head taking a Dative argument. If that argument stays in situ, then it is Dative, and if it moves to the Spec of V, it may be Case-checked by kiss moving to v. I will adopt none of these representations, because I wish to derive the properties of the shared argument of resultative constructions. Moreover, there is simplicity and elegance in the sharedargument hypothesis that is appealing.

\subsection{Resultative constructions with fake objects}

The two well-known classes of resultatives, a subclass of those like wipe clean, whose complement is a semantic object of the verb, and the class of those like tick awake, whose complement is not, have different properties, such as the ability to form adjectival participles (a wiped clean table vs. *a barked awake child). ${ }^{16}$ Dimitrova-Vulchanova (2002) labels them connected results and unconnected results, for the reason that connected results express results informing on one of the lexically implied parameters of a predicate (freeze implies the state solid, and freeze solid is a connected result, whereas bark awake is not, given that the state of being awake is not inherent in the meaning of bark). These two classes coincide with Wechsler's (1997) “control” and "ECM" (Exceptional Case Marking) 
resultatives. In addition, work such as Levin and Rappaport Hovav (2005) shows that the naturalness condition imposed on the result holds not only of connected results but also unconnected ones, so that we may talk about single events also in the case of unconnected results. For instance, world knowledge tells us that sleeping is made possible under the condition of not being troubled, by noise, nightmares, etc. And barking, which lexically contains the notion of noise, may form a resultative construction with awake for that reason. That means that even resultatives with fake objects impose a close semantic relation between the two predicates. See also Rappaport Hovav and Levin (1996).

These arguments have led me to adopt the general lines of Dowty (1979) and Williams (1994), whereby differences between two types of one and the same construction can be an effect of the point at which the construction is formed. I have concluded that the wipe clean class of resultatives is formed in the lexicon, and the bark awake class in the syntax. ${ }^{17}$ This implies that the fake-object resultative is not lexical, so let us see why. Suppose we form a lexical entry like bark awake, in which the $\mathrm{V}$ is intransitive:

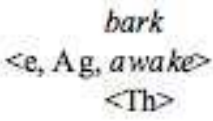

In syntax, the Adj should find an argument that could be built as its subject. The only one available is Ag, but, first, the Agent will be too high to merge with the Adj, and second, Agent is not a Theta-role congruent with the Adj. So, a form like bark the child awake crashes.

58 However, if English grammar has the capacity to express the endpoint of an event, we may assume that such a phrase can be a small clause, as in (38): ${ }^{18}$

(38)

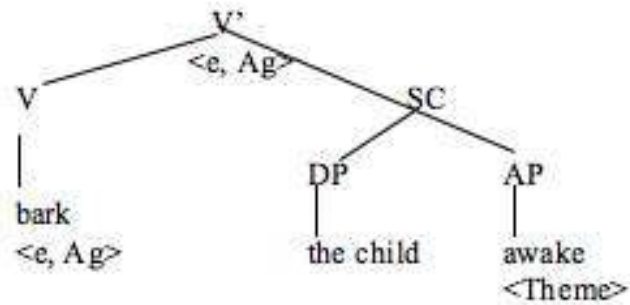

Supposing that English grammar has the capacity to form complex predicates, naming single events, in the syntax (Williams 1994), this makes the DP a syntactic complement of the complex syntactic verb, allowing it to check Case features, since the verb has a subject that is responsible for the event:

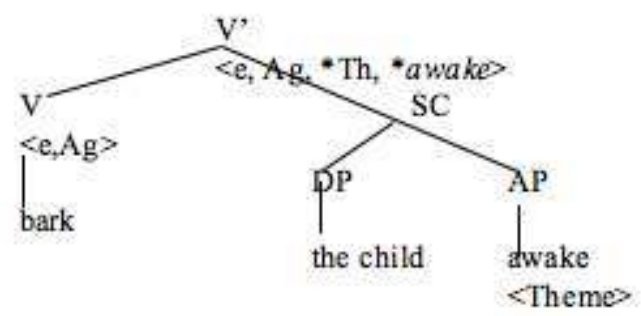



later help us analyze the kiss goodbye construction with intransitive verbs, like wave goodbye.

\section{The kiss goodbye construction}

\subsection{The account}

61 There are at least two ways to account for this construction. A first hypothesis, which I will reject, is that it would involve two predicates, one VP wish/tell/bid somebody goodbye (the presumed embedded predicate) somehowoverlapping with the matrix VP kiss somebody.We will consider a strong argument against the covert $\mathrm{V}$ in section 3.4, but note that, given the semantics of goodbye, there is no need for a covert $\mathrm{V}$ in the kiss goodbye construction. As we saw, de Cornulier (1976)'s auto-delocution mechanism makes the interjection itself refer to the act of uttering it. And, by metonymy, the interjection in the verbal construction can refer to the illocutionary act performed by that utterance.

62 The second hypothesis is that the kiss goodbye construction is a lexical resultative. This complex verb is formed by integrating the second predicate, the formulaic interjection, as the first semantic element combining with the verb kiss:

(40) kiss added with Interj yields resultative kiss $<e, x, y>\quad\langle e, x, y$, Inter $>$ $\langle\ldots\rangle$

This represents the lexical knowledge that kiss goodbye names an act of kissing, involving two participants, which reaches an endpoint named by the interjection. Given the interpretation of the interjection, that endpoint is the illocutionary act performed by the utterance of the interjection.

64 The resultative kiss goodbye construction must meet the two usual requirements on resultative constructions: first, the resultative expression kiss goodbye should name a single event, and second, the expression goodbye must name a connected result, namely, a result naturally deriving from the process named by the verb.

65 As for the first requirement, it is threatened by the number of processes mentioned in the construction, one of kissing and one of uttering the interjection. However, recall that these two different actions are able to perform the same event, that of saluting. I claim that this is what makes the kiss goodbye construction a well-formed resultative construction, explaining the manner requirement (13) of section 1.3. We can express this by identifying the interjection goodbye with the Davidsonian event place of kiss. ${ }^{19} \mathrm{As}$ with all eventive verbs, kiss saturates the $e$ position of the complex predicate, and goodbye is equated with $e$, which is indicated with coindexing the relevant variables of the complex predicate, allowing the complex verb to name one and only one event:

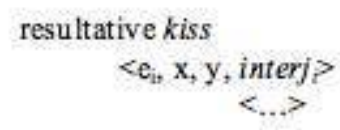

66 We see that, instead of being allowed by lexical semantic subordination, like wipe clean, the kiss goodbye construction relies on referential identity. 
67 As for the second semantic requirement of that construction, the illocutionary act performed by the utterance of the interjection can be defined as the endpoint of the main verb, since that act results, instantaneously, from the act named by the verb. In conclusion, the kiss goodbye construction respects two basic semantic conditions on resultatives.

68 Let us pursue the discussion of the syntax of kiss goodbye. Similarly to other resultative constructions, the kiss goodbye construction is the formation of a complex predicate between the matrix $\mathrm{V}$ and a subject-taking predicate expressing the endpoint of the event named by the verb. Given that the two elements that are put together in that construction are two nominals, somebody and goodbye, I assume that the relevant subjectpredicate relation is that of the double object construction, in which a nominal is defined as the subject of another nominal. ${ }^{20}$ In GB terms, that subject predicate relation is represented as a Small Clause, the subject of which is the IO and the predicate the DO, as in the analysis of the complement of have in Guéron (1995). In minimalist terms, it is represented as a relation mediated by a low applicative in Pylkkänen (2002). That applicative predicate takes the DO as its complement and the IO as its subject and it expresses a Possession relation between the two nominals. The content to be given to the notion of Possession in the kissgoodbye construction is that between the utterance act named by the interjection and the addressee of that act. In other words, in the kiss goodbye construction, first, the interjection is integrated in the verbal complex as a noun naming an act, because complex-predicate formation in English is the integration of a predicate onto the main verb. Second, by the double object construction, and owing to this particular semantic context, that act, an act of address, must be interpreted as given to some participant, consequently an addressee. Importantly, we will see in section 3.8 that some interjections, like shame on may take arguments which may be qualified as Goals too, but toward whom it is not the utterance act itself that is addressed, but the content of the interjection, and they are not allowed in the kiss goodbye construction.

69 We are now going to consider one semantic effect of the shared-argument hypothesis. This is how the derivation works. First, the complex lexical unit kissgoodbye projects in syntax in a structure in which the two heads come as merged:

(42)

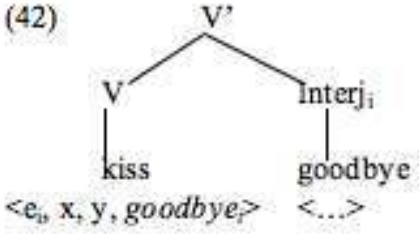

The predicative nature of the interjection forces it to have a subject, so it merges with the double object Applicative head:

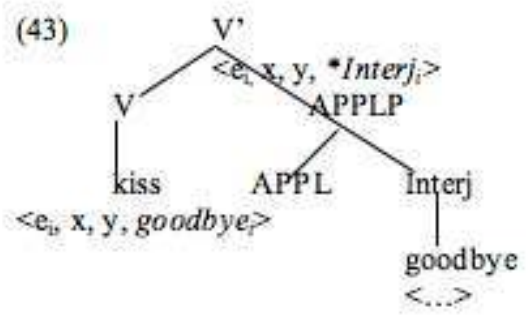


Then semantic composition may start and the two heads must see their argument places saturated. Goodbye, which is not a projecting head of the complex verb, has to find a subject in the structure. Moreover, the verb has to see its $y$ position saturated. The two requirements on the distinct predicates are simultaneously met by merging the head $\mathrm{V}$ with its complement and by convergent merging of the interjection, via APPL, with that DP:

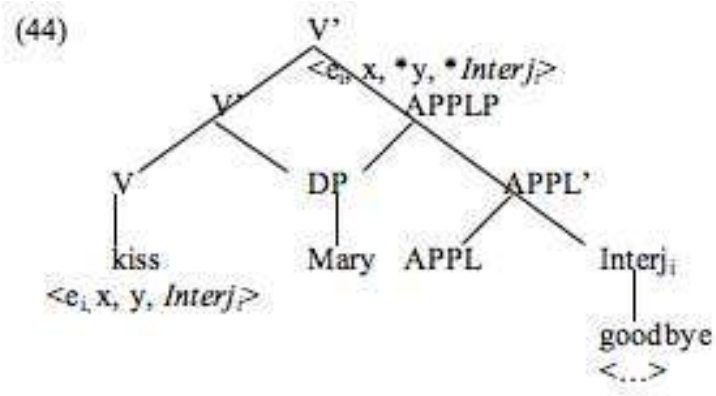

Let us now focus on the shared argument of the kiss goodbye construction. The thetacriterion forces an argument to receive at most one theta role. Given that this argument is shared by two heads, the two heads must assign the same theta-role. Given that the configuration between the two nominals is that of a double object construction, it must have its semantics, meaning that the DP must be a Goal. This means that the interjection and the verb must both assign the Goal role. This is actually what happens, all the interjections that belong to that construction take addressees, and the only verbs that are compatible with the kiss goodbye construction are verbs of contact, deriving the descriptive generalization (31) of section 1.4. ${ }^{21}$

The integration of the head goodbye in the theta-grid of kiss does not alter the semantics of that theta-grid, to the effect that Agent and Goal are still interpreted as the higher and the lower arguments of kiss, but, in addition, the Goal argument is the syntactic subject of the interjection, forcing it to be the addressee of that interjection.

\subsection{The complex predicate is a verbal unit}

Let us now consider why such complex predicates are possible concerning Case or theta requirements. Given that the verbal element kiss goodbye has an argument that brings about the process that it names, the interjection goodbye may check an Accusative feature. I suppose English has the general capacity to Case-check the other internal argument as a dative, all semantic conditions being respected, which allows the argument $y$ to be analyzed as a dative. This Case analysis carries over to the prepositional construction. In the prepositional frame, kiss goodbye to something, goodbye has the status of the DO, and something that of the IO, as evidenced by the preposition to. ${ }^{22}$ This preposition comes from some other device than lexical selection since the verb kiss does not subcategorize for it. It must be the dative Case-marker, as proposed by Rouveret and Vergnaud (1980) (see also Kayne 1977) for the French Dative Case marker à 'to' of the causative construction, and Larson (1988) for English double object constructions. ${ }^{23}$ If this Case-based account is right, it shows that goodbye is a structural DO (nominal sister to V), since its presence triggers Dative Case checking, whereas without goodbye, it is the usual DP complement that checks Accusative (kisssomebody). 
The competition for Accusative explains why, similarly to other resultative constructions like (45a), the kiss goodbye construction may not have two DOs, as in (45b) and as mentioned in section 1.3.1:24

(45) a. *He wiped the table the top clean.

(46)b. *He blew a kiss to his idea goodbye. (blow a kiss = "kiss")

\subsection{The kiss goodbye construction with intransitive verbs}

76 Let us now briefly consider intransitive matrix verbs, like wink, for which acceptability judgments vary:

(46) $\left(^{*}\right)$ He winked them goodbye.

These are constructions with fake objects, on a par with the bark awake resultative. Recall that I have shown that fake-object resultatives can only be built in the syntax. Suppose it was built as a word:

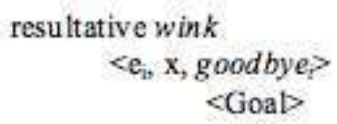

This is not excluded for Case reasons. Given that the subject of wink goodbye is responsible for the process named by this verbal predicate, the Accusative feature may be ckecked. The reason why it is excluded is that the interjection goodbye is a predicate and thus should have a subject, saturating its Goal place. The interjection is not the projecting head of the verbal complex, so it cannot project a structure up, and given that the verb does not provide that argument, the structure crashes. That is why certain speakers reject such forms. This fact sheds light on a general property of lexical resultative constructions, which is that the frame of complementation is built from the verb. In order to obtain the complex predicate $V$ goodbye, the $\mathrm{V}$ must have at least one internal argument, which it shares with the interjection.

79 However, certain speakers accept such forms. For these speakers, the complex predicate is formed in the syntax. The syntactic formation of wink goodbye is done by merging the $\mathrm{V}$ wink with the applicative construct $\left[_{\mathrm{APPLP}}\right.$ Mary $\left[_{\mathrm{APPL}}\right.$, APPL goodbye $\left.]\right]$. The thing that complex-predicate formation does is make the complex verb wink goodbye behave like a simple verb, naming one event, with Case properties of transitive verbs, as was illustrated for fake object resultatives in section 2.2. Interestingly, the syntactic merging of the verb with the double-object Applicative construct yields the structure of an ordinary double object construction, to which we return in section 3.6:

(48)

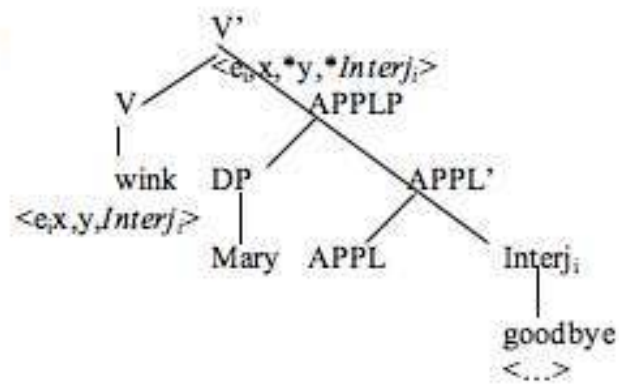




\subsection{No covert V}

80 I have not used a covert V to account for the meaning of 'wish' or 'say' or 'bid', etc., in the kissgoodbye construction. It is interesting to note two things. First, the hidden $\mathrm{V}$ is not necessarily wish, because some formulas are not wishes and are consequently incompatible with that verb (*wish so long/hello/hi/thanks, etc.). This means that the kiss goodbye occurrences would have to choose their covert $\mathrm{V}$ according to the formula. That is not a problem, but it is worth noting that, if there were only one covert $\mathrm{V}$, its meaning should be able to cover the meanings of all the overt verbs that subcategorize for all these formulas.

81 Second, and more importantly, some formulas, like hi, thanks and solong cannot occur delocutively with ditransitive verbs (cf. (49a)), but only with prepositional verbs, like say, but they may nevertheless enter the kiss goodbye construction (cf. (49b)):

(49)a. *Go tell/bid/wish your aunt hi/hello/so long. (vs. Say hi/hello/so long to DP)

25

(49)b. Go kiss your aunt hi/so long.

82 If there indeed were a covert verb in the kiss goodbye construction with these interjections, that would mean that there exists a covert $\mathrm{V}$ of utterance with no overt counterpart, not an appealing conclusion. Moreover, if these interjections cannot be arguments of ditransitive verbs, that must be for a semantic reason, which should also be respected if there were a covert verb, leaving sentences like (49b) unexplained.

83 So, there is no covert V. But, then, we may wonder what allows those interjections in the particular ditransitive structure of the kiss goodbye construction. The claim here is that they do not occur in the structure as selected arguments. In the present dual analysis, any word is allowed in principle to enter this resultative frame, so long as it is a predicate naming an endpoint. This is how goodbye, thanks and all the other interjections happen to enter the particular double object frame of the kiss goodbye construction, independently of whether they may themselves be complements of a double object verb of utterance. That is a crucial point.

\subsection{The restriction to interjections}

84 To pursue the discussion just raised, there are no sentences like *they hit him a broken nose, *they thanked him a new car, they convinced him a new car, etc., in which the direct object would be interpreted as an indirect object, here meaning 'they hit him to the point of breaking his nose', 'they thanked him by giving him a new car', 'they convinced him that he would have a new car,' etc. This means that, even though English grammar possesses a broad array of conflation structures, it is strongly limited with the $\mathrm{V} \mathrm{N}_{1} \mathrm{~N}_{2}$ structure. The speaker may induce a restriction on the $\mathrm{N}$ from the occurrences they hear and the absence of occurrences like *they hit him a broken nose, etc., which, if there were no constraints on the construction, would occur. I think, in accordance with a great number of authors, such as Goldberg (1995), that negative evidence may be built by the speaker, and may count as evidence on which to ground rule formation. However, evidence may be induced if the speaker asks the right questions. From observation, a formula is not an ordinary noun and in particular, it does not name a participant. The element goodbye that is added is a subject-taking predicate, which constitutes the speaker's positive evidence, 
who can conclude that kissgoodbye belongs to the resultative family (Goldberg and Jackendoff. 2004). S/he thus compares and distinguishes goodbye, an interjection naming an act, from ordinary argument DPs, which are not eventlike and thus are unable to enter the particular resultative $\mathrm{V} \mathrm{N}_{1} \mathrm{~N}_{2}$ frame that (s)he has deduced. According to me, the restriction of $\mathrm{N}_{2}$ to interjections is a strong argument in favour of the resultative analysis of the kiss goodbye construction.

There are cases in which Nouns or full DPs form complex predicates with verbs, such as pay attention to (Jayaseelan 1988). In that case, they saturate an argument-place in the theta-grid of the predicate, they are not added to it, as opposed to resultative constructions.

\subsection{Is kiss goodbye a double object construction like wave goodbye?}

First, let us repeat that goodbye has the DO quality of an Accusative object:

(50) a. He kissed her goodbye.

(50)b. Let us kiss goodbye to breast cancer.

This pair displays on the surface the usual alternation between the prepositional and the ditransitive order of a double object construction, with goodbye the Accusative object. Consequently, the kiss goodbye construction could be a simple double object construction, like wave goodbye. However, recall from section 3.4 that some interjections are incompatible with double object verbs, like hi and so long (*tell sb hi/so long, ${ }^{*}$ wish sb hi/so long) and can nevertheless enter the kiss goodbye construction, which would be puzzling if kiss goodbye were an ordinary double object construction.

In the present dual analysis, the kiss goodbye construction is a resultative construction which has a double object configuration between two nominals. The Goal is an IO insofar as its superficial syntax (VP-internal subject in a construction with two nominals) and semantics (Goal) is concerned and insofar as the prepositional equivalent with to (kiss goodbye to) also has the semantic and syntactic flavour of a double object construction. But the Goal is built as the DO of kiss in a resultative construction, with the second element an added predicate, as in other resultative constructions. The aim of this section is to show that the kiss goodbye construction (the structure with kiss below) is not a simple double object construction like the construction with wave below (based on Pylkkänen 2002), and that the dual analysis may account for the differences between the two:
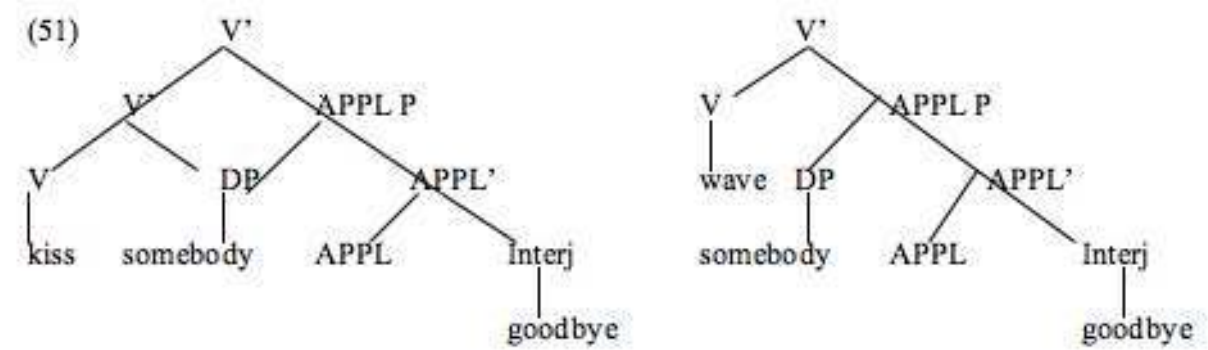

One first difference between kiss goodbye and wave goodbye is that, with wave, the interjection may head a full DP with a genitive, which is impossible with kiss goodbye:

(52) a. He waved/smiled me his thanks.

(52)b. *He kissed me his thanks. 
Let us now test the syntactic properties pertaining to the grammatical functions of the two nominals of the construction in turn. Apart from the first property below, which will not be conclusive, the other properties will show that the Goal behaves like an ordinary DO rather than the IO of a double object structure.

91 The first property is passivization. The IO passivizes easily in double object constructions:

(53)a. He was given good advice.

92 The Goal of kiss goodbye and wave goodbye passivizes well:

(54)a. She got too old to be kissed goodbye when her mother dropped her off at school.

(54)b. The crew need to be waved goodbye.

As I mentioned, we cannot say why the Goal in (54a-b) passivizes well. It could be that it is because it is the IO of a pure double object construction, or because it is the DO of the verb kiss in a resultative construction, as claimed here.

We now turn to properties, like wh extraction, that show that the kissgoodbye construction is not an ordinary double object construction. In general, the IO of a double object construction does not relativize easily:

(55) *Here is the person they gave advice.

But the Goal of kiss goodbye does, contrary to the Goal of wave goodbye:

(56)a. Here is the person you should kiss goodbye.

(56)b. *Here is the person you should wave goodbye.

One could think that wh-extraction of the Goal in the kiss goodbye construction is possible because kiss and goodbye form a kind of idiomatic expression, but that is not verified with other V-IO-DO idiomatic expressions:

(57) *Here is the person they gave the thumbs up.

97 The present resultative analysis can explain these facts, because the Goal is the DO of the verb, and wh-extraction of that object meets no difficulty in resultatives in general:

(58) What table did you wipe clean?

Another difference between the IO of a double object construction, like wave goodbye, and the Goal of kiss goodbye is that, normally, IOs of double object constructions may be omitted, whereas the Goal of kiss goodbye may not:

(59)a. *Kiss goodbye, John!

(59)b. Wave goodbye, John!

This behaviour of the DP of the kiss goodbye construction is specific to DOs. In general, DOs cannot be omitted, and this is verified for kiss and verbs of contact, as in (60a), and verified for resultatives too, as in (60b):

(60)a. *John kissed/hit/patted, etc.

(60)b. *John wiped clean.

In conclusion, the Goal of kiss goodbye does not have the general syntactic properties of an IO in a double object construction, but rather that of a DO, which is compatible with the present analysis, in which it is the DO of a resultative construction.

101 Next, let us turn to the other complement of the construction. It is built as the predicate of a resultative construction, yielding an $\mathrm{N}$ in a double object configuration. We are going to see that it has some syntactic properties of DOs in a double object construction, but not 
all. It behaves like the DO of a double object construction in resisting passivization (??a book was given him) whether it is a noun, as in (61) or a full DP, as in (62):

(61) *Goodbye was kissed him.

(62) *A sad goodbye was kissed him

As for the prepositional construction, the $\mathrm{N}$ goodbye does not passivize, as in (63a) but it may passivize (with slight reluctance) when it heads a DP, as in (63b), like usual DOs in the prepositional construction, as with wave in (63c):

(63)a. ${ }^{*}$ Goodbye was kissed to freedom.

(63)b. ?A sad goodbye was kissed to freedom.

(63)c. A sad goodbye was waved to our friend.

Things are different with wh-extraction. It does not question well, contrary to the DO of a double object construction:

(64)a. ??How passionate a goodbye did she kiss him this time? ${ }^{26}$

(65)b. How passionate a goodbye did she wave him this time?

104 I will not provide an explanation of this behaviour, though this difference with ordinary DOs of double object constructions could bear on the predicative nature of goodbye in the kiss goodbye construction. Moreover, goodbye is an $\mathrm{N}$ in kiss goodbye, whereas it must be a full DP with wh extraction, and that difference could be relevant. What is important here is that there indeed is a difference with pure double object constructions and kiss goodbye.

The tough-construction too illustrates a difference between kiss goodbye and a pure double object construction:

(66)a. *That sad goodbye was not easy to kiss.

(66)b. That sad goodbye was not easy to wave.

106 I will propose that the behaviour of goodbye with respect to the tough construction is due to its predicative nature. This noun seems close to an overt form of the noun that underlies cognate objects. Cognate objects overtly realize an underlying noun that lexically doubles intransitive verbs denoting activities of the body like die or smile: ${ }^{27}$

(67) He smiled a wry smile.

In general, authors agree that cognate objects are syntactic DOs (they cannot be separated from the V by an adverb, they bear structural Case in languages that have morphological Case, etc., as shown in Mittwoch 1998, Massam 1990 and Real Puigdollers 2008 among others), and that the particular properties that distinguish them from ordinary objects are semantic. Like cognate objects, goodbye must be modified when it has a (indefinite) determiner:

(68)a. He smiled a wry smile/*a smile

(68)b. He kissed his mother a sad goodbye/*a goodbye. similarities (see (66)):

(69) *That sad smile was not easy to smile.

Lastly, morphology too shows that goodbye is not a pure DO in a double object construction. For instance, goodbye does not behave like an argumental DO in that it cannot form a Ving-compound, as shown in (70a), compared with (70b):

(70)a. *goodbye-kissing to kiddos

(70)b. ?candy-giving to kiddos

110 To conclude, the kiss goodbye construction has the properties of a double object construction as concerns Case and Theta roles, but the Goal has syntactic properties of 
the DO of a transitive verb in a resultative construction. As for goodbye, it is an Accusative noun with properties of a cognate object and it does not have all the properties of the DO of a double object construction. The mixed structure proposed here, in which the Goal is both a DO and an IO, and in which the Accusative goodbye functions like the added predicate of a resultative construction is coherent with these findings.

\subsection{Why a kiss sorry card but *kiss somebody sorry?}

111 This section presents evidence for the lexical nature of the kiss goodbye construction. Consider:

(71) *kiss somebody sorry/*kiss sorry to somebody

112 These verbal expressions are excluded. That is because sorry does not license an addressee:

(72) *Sorry to you.

113 Considering (71), the interjection is a predicate, so it must have a subject when it builds its syntax, but it does not accept a subject, an addressee, as shown in (72). In other words, lexical resultatives must all add an argument-taking predicate onto the verb. So, the only interjections that may function in such resultatives are argument-taking interjections.

114 Now, kiss sorry may be a word, an $\mathrm{X}^{\circ}$ form:

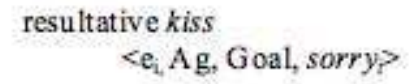

This form says that kissing somebody and saying sorry perform the same illocutionary act, involving two individuals. Given that it does not enter the syntax as a projecting verb, there is no requirement for a subject to sorry. So, there is, at the lexical level, nothing wrong with the fact that the interjection does not license an addressee. ${ }^{28}$ Then nominal conversion may apply to that form, yielding the noun kiss sorry:

(74) a kiss sorry card, free kiss sorry mobile background, kiss sorry wallpaper, etc.

\subsection{Insults}

Consider the insult stupid or the deprecatory expression shame (on). The latter interjection may occur with an argument that is a Goal, the location of the thing named by the N:

(75)a. You stupid!

(75)b. Shame on you!

117 And these interjections may be used delocutively:

(76)a. In this case, I say stupid. (internet source)(76)b. Teamsters Say Shame on

Fiat/Chrysler at Italian Consulate. (internet source)

So, we could think that they are able to enter the kiss goodbye construction, but they may not:

(77)a. *He nudged him stupid.

(77)b. *Bob slapped Albert shame.

There are two competing and presumably conspiring conditions that explain this. ${ }^{29}$ First, the identity requirement on the two acts. The physical acts named by the events of the sentences above, nudging or slapping and the speech act of uttering "stupid!" 
or"shame!"do not perform the same illocutionary act. The act of uttering "shame!" performs an insult or a curse. The acts of nudging or slapping can perform the act of closing a social exchange or a social relation, but not an insult or a curse..$^{30} \mathrm{So}$, nudge stupid or slap shame are not possible forms, even if nudging or slapping are perfectly suited to situations in which one utters "stupid!" or "shame!".

second reason why such forms are excluded is that the interjection does not take an addressee, meaning that the internal argument of the interjection in (75) above is not its addressee:

(78)a. *Stupid to you!

(78)b. * shame to you!

Considering shame on you, the participant is one towards whom the emotion of shame is directed and in that sense it is a Goal, but the Goal of the content of the interjection, not the Goal of the act of uttering the interjection. In other words, the internal argument of (75b) above is not the addressee of the interjection.

However, note that it is possible to const
constructions like wave goodbye, with insults:

(79) Brother Benedict would have sneered that he was a man with one eye, a cyclops, would have sneered coward at him, would have called him a moral

degenerate. (Bernard MacLaverty, Lamb, 1980 Jonathan Cape, 2000 Vintage, p. 141)

The two acts, sneering, and interjecting "coward!" refer to the same illocutionary act of signalling contempt. Even though the insult does not itself license an addressee, $\left({ }^{*}\right.$ coward to you!), the participant to which the insult is addressed may be introduced by the PP at him. As shown earlier in the contrast of (59a-b) (*kiss goodbye, John/wave goodbye, John), complex verbs formed in syntax do not have to express the addressee. That means that the interjection is not faulty in this construction if it does not license an addressee by itself.

\section{Conclusion}

I have claimed that the grammar of English, first, allows the integration in the lexicon of an interjection, the interjection a formula, into the theta grid of a predicate, similarly to the mechanism that forms lexical resultative constructions. In such constructions, the second predicate is not the projecting head of the complex verb, but needs a subject, forcing argument-sharing with the verb. Often, resultatives, whether English-type resultatives or serial-verb resultative constructions, have a shared Theme and the interest of this construction is that it displays a shared Goal, confirming the argumentsharing property of this class of complex predicates. The syntax and semantics of the kiss goodbye construction is a blend of a resultative construction and a double object construction, which his accounted for by the idea that it is a resultative construction the predicate of which is nominal, forming an $\mathrm{N}_{1} \mathrm{~N}_{2}$ structure which is a double object configuration.

Second, a complex verb can only name a single event, so the interjection is not allowed to name another event than that named by the verb. We have been able to determine that the uniqueness condition is respected when we take into account the illocutionary act performed by the action named by the $\mathrm{V}$ and that performed by the utterance of the interjection. These two acts must be the same. 
126 The kiss goodbye expression sounds natural when it names strict social conventions and more creative when it is formed either on more creative gestures (hug somebody goodbye) or on more creative interjections (kisssomebodygood luck) or both (hug somebody good luck). The last ones, which lexically contain neither kiss nor goodbye are less easily accepted. In addition to the lexical kiss goodbye, there is a syntactic kiss goodbye construction, equivalent to fake object resultatives, the wave goodbye construction, which has properties of a double object construction.

128 Lastly, the kiss goodbye construction is one rare striking construction for which it may be shown that a nominal bears two grammatical functions at the same time (a DO and an IO). And if that is true of that construction, and if this construction instantiates the family of lexical resultative constructions, then it means that all lexical resultative constructions display this kind of blend, in which one DP is the argument of two heads.

This construction has led us to investigate one case of delocution, the integration of emotive or expressive linguistic objects into words or syntax, and how revealing that is for grammar.

\section{BIBLIOGRAPHIE}

Ameka Felix 1992a. 'Interjections: The universal yet neglected part of speech', Journal of Pragmatics 19(2), 101-108.

Ameka Felix 1992b. 'The meaning of phatic and conative interjections,' Journal of Pragmatics 18, 245-271.

Anscombre Jean-Claude. 1986. 'Délocutivité généralisée.' Recherches linguistiques de Vincennes, 5-43. Saint-Denis : Presses universitaires de Vincennes.

Austin John L. 1962. How to do Things With Words. (1970) French translation by Gilles Lane, Postface by François Récanati. Quand dire, c'est faire. Paris : Editions du Seuil.

Baker Mark 1988. Incorporation: a Theory of Grammatical Function Changing. Chicago: University of Chicago Press.

Baker Mark. 1989. 'Object sharing and projection in serial verb constructions.' Linguistic Inquiry 20:513-555.

Baker Mark and Osamuyimen T. Stewart. 1999. 'On double-headedness and the anatomy of the clause.'

http://citeseerx.ist.psu.edu/viewdoc/download?doi=10.1.1.39.6340\&rep=rep1\&type=pdf

Barss Andrew and Howard Lasnik. 1986. 'A Note on anaphora and Double Objects.' Linguistic Inquiry 17, 2: 347-354.

Benveniste Emile. 1966. Problèmes de linguistique générale. Paris: Gallimard.

Boas Hans C. (2003) A Constructional Approach to Resultatives. Center for the Study of Language and Information. Chicago: University of Chicago Press. 
Bouchard Denis. 1995. The Semantics of Syntax: A Minimalist Approach to Grammar. Chicago: University of Chicago Press.

Brandt Patrick. 2000. 'In the Double Object Construction.' In Hellen de Hoop and Ton van der Wouden (eds.), Linguistics in the Netherlands. Amsterdam: Benjamins.

Burzio Luigi. 1986. Italian Syntax : A Government and Binding Approach. Dordrecht: Reidel.

Carrier J and J. H. Randall. 1992. 'The Argument Structure and Syntactic Structure of Resultatives.' Linguistic Inquiry 23,173-234.

Copard Maxime. 2009. 'Implicit and Explicit Body-Parts in English Verbal Constructions'. Master's thesis. University of Caen, France.

de Cornulier Benoît. 1976. 'La notion de dérivation délocutive.'Revue de linguistique romane 40, 116-144.

Dimitrova-Vulchanova Mila. 2002. ‘On two types of results: resultatives revisited.' Ms NTNU Trondheim. http://74.125.155.132/scholar?q=cache:umA0XUL-ukQJ:scholar.google.com/+DimitrovaVulchanova+Mila.+2002\&hl=fr\&as_sdt=2000

Dowty David. 1979. Word Meaning in MontagueGrammar. Dordrecht: Reidel.

Dowty David. 1991. 'Thematic Proto-Roles and Argument Selection.' Language 67, 547-619.

Fradin Bernard. 2003. 'Delocutive adverbs in French.' Paper read at the $10^{\text {th }}$ International Morphology Meeting, Szentendre, Magyarorszag. Draft available online: http:// llf.linguist.jussieu.fr/llf/Gens/Fradin/IMM10-txt-form.pdf

Goldberg Adele. 1995. Constructions: A Construction Grammar Approach to Argument Structure. Chicago \& London: The University of Chicago Press.

Goldberg Adele and Ray Jackendoff. 2004. 'The English Resultative as a Family of Constructions.' Language 80, 532-568.

Gruber J. S. 1970. Studies in lexical relations. Indiana University Linguistics Club.

Guéron Jacqueline. 1995. 'On HAVE and BE,' in Proceedings of NELS 26, 191-206. Amhert MA: GLSA.

Haïk Isabelle. 2005a. 'Les métonymies verbales'. In Grammaire et figures de style, Claude Delmas et Jacqueline Guéron (eds.), Presses de la Sorbonne Nouvelle.

Haïk Isabelle. 2005b. 'Marrant et les adjectifs comme ça.' Lingvisticae Investigationes 28, 189-234.

Harley Heidi. 2002. 'Possession and the Double Object Construction.' In Linguistic Variation Yearbook 2, 29-68. John Benjamins Publishing Company.

Harley Heidi. 2005. 'How do verbs get their names? Denominal verbs, Manner Incorporation and the ontology of verb roots in English.' In Nomi Erteschik-Shir and Tova Rapoport (eds.) The Syntax of Aspect, 42-64. Oxford: Oxford University Press.

Higginbotham James. 1985. 'On Semantics.' Linguistic Inquiry 16, 547-593.

Hoekstra Teun. 1988. ‘Small Clause Results.' Lingua 74, 101-139.

Jackendoff Ray. 1972. Semantic Interpretation in Generative Grammar. Cambridge, MA: MIT Press.

Jackendoff Ray. 1990. Semantic Structures, Cambridge, MA: MIT Press. 
Jayaseelan K.A. 1988. 'Complex Predicates and Theta-Theory'. Syntax and Semantics 21. Semantic Relations W. Wilkins (ed.). San Diego, California: Academic Press.

Jung Yeun-Jin and Shigeru Miyagawa. 2004. Decomposing Ditransitive Verbs'. In Proceedings of SICGG, Summer 2004, 101-120.

Kayne R. S. 1977. French Syntax: The Transformational Cycle. Cambridge, MA: MIT Press.

Kayne R. S. 1984. Connectedness and Binary Branching. Dordrecht: Foris.

Kiparsky Paul. 1977. 'Remarks on Denominal Verbs.' In A. Alsina, Joan Bresnan, and Peter Sells (eds.), Complex Predicates. Stanford, CA: CSLI Publications, 473-99.

Kratzer Angelika. 2005. 'Building Resultatives'. In Maienbaum, Claudia and Angelke WöllsteinLeisen (eds.). Event arguments in Syntax, Semantics, and Discourse. Tübingen: Niemeyer.

Larson Richard. 1988. 'On the Double Object Construction.' Linguistic Inquiry 19, 335-391. Cambridge, Massachusetts: MIT Press.

LevinBeth. 1993. English verb classes and alternations: A preliminary investigation. Chicago: University of Chicago Press.

Levin Beth and Tova R. Rapoport. 1988. 'Lexical Subordination.' In Proceedings of the 24th Annual Meeting of the Chicago Linguistic Society, 275-289.

Levin Beth and Malka Rappaport. 1995. Unaccusativity: At the syntax-lexical semantics interface. Cambridge, MA: MIT Press.

Levin Beth and Malka Rappaport Hovav. 1999. 'Two Structures for Compositionally Derived Events.' In Proceedings of the SALT conference, 199-223. Chicago: CLS Publications.

Levin Beth and Malka Rappaport Hovav. 2005. Argument Realization. Cambridge, UK:Cambridge University Press.

Lieber Rochelle. 1983. 'Argument Linking and Compounds in English.' Linguistic Inquiry, 14, 251-286.

Manning C., Ivan Sag and C. Iida .1999. 'The Lexical Integrity of Japanese Causatives.' In R. D. Levine and G. M. Green (eds.) Studies in Contemporary Phrase Structure Grammar, 39-79.

Manzini M.-Rita. 1983. Restructuring and Reanalysis. Ph D dissertation, MIT, Cambridge, MA.

Massam Diane. 1989. 'Part-Whole Constructions in English.' In J. Fee and K. Hunt (eds.) Proceedings of the West Coast Conference in Formal Linguistics, 236-246. Chicago: University of Chicago Press.

Massam Diane. 1990. 'CognateObjects as Thematic Objects.' The Canadian journal of linguistics 35:22, 161-190, University of Toronto Press.

Mateu Jaume. 2001. 'Small Clause Results Revisited'. In ZAS Papers in Linguistics, vol. 26: Syntax of Predication, Nina Zhang (ed.), Berlin. Also distributed electronically: http://www.zas.gwzberlin.de/papers/zaspil/infos/index.htm

McIntyre Andrew. 2004. 'Event paths, conflation, argument structure and VP shells.' Linguistics, 42,523-571, Walter de Gruyter.

Mittwoch Anita. 1998. 'Cognate objects as reflections of Davidsonian event arguments.' In Susan Deborah Rothstein (ed.) Events and grammar, 309-332. Kluwer academic publisher.

Pylkkänen Liina. 2002. Introducing Arguments. Ph.D. dissertation, MIT, Cambridge, MA. 
Ramchand Gillian. 2008. Verb meaning and the lexicon: a first phase syntax. Cambridge University Press.

Rappaport Hovav Malka and Beth Levin. 1996. 'Two Types of Derived Accomplishments.' In M. Butt and T.H. King (eds.) Proceedings of the First LFG Conference, 375-388.

Real Puigdollers Cristina. 2008. 'The nature of cognate objects.' In Proceedings of conSOLE XVI, 157-178. University of Leiden.

Ritter E. and Sarah Rosen. 1998. 'Delimiting Events in Syntax.' In M. Butt and W. Geuder (eds.) The Projection of Arguments, Stanford, CA. Center for the Study of Language and Information, 135-164.

Rothstein Susan. 1983. The syntactic forms of predication. Doctoral dissertation, MIT. Published in Bloomington: Indiana University Linguistics Club 1985.

Rouveret Alain and Jean-Roger Vergnaud. 1980. 'Specifying Reference to the Subject: French Causatives and Conditions on Representations.' Linguistic Inquiry 11, 97-202.

Simpson Jane. 1983. 'Resultatives.' In Levin, Rappaport and Zaenen (eds.) Papers in Lexical Functional Grammar, IULC.

Stowell Tim. 1983. 'Subjects across categories.' The Linguistic Review 2, 285-312.

Talmy Leonard. 1991. 'Path to realization: a typology of event conflation' in Proceedings of the Berkeley Linguistics Society 17, 480-520.

Tenny Carol. 1994. Aspectual Roles and the Syntax-Semantics Interface. Dordrecht: Kluwer.

van Voorst Jan.1988. Event Structure. Current Issues in Linguistic Theory 59. Philadelphia and Amsterdam: John Benjamins.

Wechsler Stephen. 1997. 'Resultative predicates and control.' In Proceedings of the 1997 Texas Linguistics Society Conference: 307-321. University of Texas at Austin: Texas Linguistics Forum 38 .

Winkler Susanne. Focus and secondary predicates. Berlin: Mouton de Gruyter.

Wierzbicka Anna. 1992. 'The Semantics of Interjections.' Journal of Pragmatics 18, 159-192. NorthHolland.

Williams Edwin. 1980. ‘Predication.' Linguistic Inquiry 11, 203-238.

Williams Edwin. 1994. Thematic Structure in Syntax, Cambridge, MA: MIT Press.

Zubizarreta Maria-Luisa. 1985. 'The Relation between Morphophonology and morphosyntax: the Case of Romance Causatives.' LinguisticInquiry 16, 247-289.

\section{NOTES}

1. I wish to thank Mark Authier, Claude Guimier, Jacques François, Emmanuelle Roussel, Richard Renault, Richard Kayne, Peter Svenonius, Rémi Camus, Ray Jackendoff, Lars Hellan, Norbert Hornstein and the members of CRISCO at the University of Caen as well as the audience of the University of Marne-la Vallée for very helpful comments. I am grateful to the reviewers of this work, who have carefully read and criticized the article, convincing me of the importance and originality of certain claims.

2. This may also be said of regular resultative constructions. In John wiped the table clean, the table is at the same time an argument of wipe and an argument of clean. Researchers have dealt with 
this problem by introducing covert elements, like PRO subject of a small clause, as critically discussed in Carrier and Randall (1992) or by saying that the verb actually does not have the DP as its argument, as in Hoekstra (1988). In this article, I am claiming that syntactic and semantic theory allows bi-headed words sharing their complement, as in Baker (1989).

3. Throughout the article, I will use single quotation marks to mention a meaning and double ones to mention an utterance.

4. As soon as one departs from kiss goodbye, speakers feel that the expression sounds creative, and they differ in the extent to which they allow new forms. Kiss somebody happy birthday is excluded by my informants, for a reason I cannot explain, but one finds a few occurrences on the internet. Sorry, to which we come back in section 3.7, is not acceptable (??He kissed his mother sorry ). We will see that it is because it does not take an addressee.

5. Additionally, welcome does not sound good in delocution in general (see section 1.2.2), which would explain why kiss welcome sounds marginal to certain speakers: (i) *Did you say welcome to your aunt? ('did your greet her, with or without uttering “welcome!"?'). But as an indefinite DP referring to an act of greeting, it sounds fine in the kiss goodbye construction: (ii) She had kissed her daughter a warm welcome.In this article I have not had the space to study the construction in which the interjection heads a full DP but this obviously deserves attention.

6. Marc Authier has mentioned to me the existence of godspeed, a wish uttered on departure for a journey. This rare and archaic word, which comes from the expression God speed you, 'may God watch over you,' has not been accepted by young speakers ( ${ }^{*} H e$ kissed her godspeed).probably because they would not allow themselves to play with an unusual word, but it has been accepted by an anonymous reviewer.

7. De Cornulier signals other cases of auto-delocution, such as cry wolf, or crier au secours, literally 'cry help'. De Cornulier discusses the semantic relation between dire 'say' and merci 'thanks' and treats dire as a kind of light verb. See Fradin (2003) for other cases of delocution and Haïk (2005a) for verbal metonymies. Anscombre (1986), basing himself on de Cornulier's work, shows that there are four possible metonymic stages in delocution.

8. "Cheers" is conventional (expected of someone in a specific situation), and it is allowed as a delocution: (i) Shoppers say cheers to safe driving. (internet source). I do not know whether the kiss goodbye construction with cheers is possible, because I have not found a transitive verb with a human complement that could describe the gesture done when one proposes a toast. An anonymous reviewer suggests the verb toast, but that verb does not take a Goal, a requirement of that construction (cf. section 1.4): (ii) *I toasted them cheers.

9. Verbs like wave, nod, shrug, etc. occur with a body-part DO, wave one's hand, nod one's head, shrug one's shoulder, etc., which is optional syntactically but compulsory semantically (Copard 2009). Interestingly, they may enter the kiss goodbye construction, even though two DOs seem to compete for Accusative checking: (i) wave one's hand goodbye. (ii) nod one's head yes. We may assume that the total redundancy of the DP makes it escape the need for Accusative checking. So, expressions like as (i) and (ii) are on a par with (24). But note that (i)-(ii) may not be construed with the addressee, a question I will leave pending: (iii) *wave somebody one's hand goodbye/*wave one's hand somebody goodbye

10. The following has been rejected by my informants: (i) *He squeezed her arm goodbye. That is presumably because squeezing someone's arm is a less conventional sign of departure than petting one's head or shaking one's hand, as in (29)-(30).

11. For Ritter and Rosen (1998), a clause names an event if one of the two functional categories that delimitate an event is activated, either the functional category that specifies the initiator of the event, or the one that delimitates it. English is a D(elimitation)-language, a language that activates the functional head that specifies an endpoint, allowing the clause to be interpreted as an event. 
12. See Baker and Stewart (1999) for nice arguments showing that there is a shared argument in the syntax of serial resultative constructions. The similarities between resultative serial-verb constructions and English resultatives are striking, and it would be fruitful to have a unifying view of them.

13. I refer to Cause as the subject of psychological verbs like annoy or physical verbs like itch.

14. Winkler (1997) too stipulates the condition that when complex predicates are formed, the argument of the Adj. must be identical to that of the verb.

15. In Larson (1988)'s analysis of double object constructions, the prepositional complement is the first element that combines with the verb. It is not so with kiss goodbye. If we assume that compositionality of meaning requires the verb to combine first with the element with which it forms a semantic unit, then goodbye combines first with kiss. This is evidenced by a compound like a kiss goodbye, granting that compound formation is a case of saturation and that this saturation operation respects the order of the arguments of the theta grid.

16. The shared-argument hypothesis leads me to claim that those like kick open, in which kick assigns Goal and open Theme are syntactic resultatives rather than morphological ones, even though the DO is a semantic object of the verb. Semantics corroborates this, because the result expressed by open is not lexically entailed by kick, which does not necessarily entail the opening or closing of doors. Whereas wipe contains the meaning 'clean', since it names an act done in order to remove dust, stains, etc., (see Dimitrova-Vulchanova 2002). This means that not all transitive resultatives are lexical, and, in particular those with verbs of contact, like kick open. Then, as discussed in the literature, the fact that DP necessarily corresponds to the DO of the verb is obtained by entailment, given the general meaning of resultatives requiring direct causation between the act named by the verb and the result named by the adjective. For example, John kicked the door open is interpreted word for word as 'John opened the door by kicking', this proposition entailing that John opened the door by kicking it.

17. I adopt the traditional view that syntax builds from $X^{\circ}$ units, and that the rules of the lexicon are formations of $\mathrm{X}^{\circ}$ units. $\mathrm{X}^{\circ}$ units and phrases often differ cognitively in that, in performance, most words are retrieved from memory, whereas most sentences are built on the spot. But these properties are not definitions of the two combinatorial spaces, given that we may memorize units bigger than $\mathrm{X}^{\circ} \mathrm{S}$ and make up new words ( $\mathrm{X}^{\circ}$ units) in speech.

18. Actually, the theory of such constructions must be able to express that any word may be inserted in the V position of such resultatives, as discussed in Jackendoff (1997) (shoulder one's way, while the time away, etc.) and Mateu (2001), but that is not central here.

19. Thanks to Norbert Hornstein for a suggestion on the use of $e$.

20. Since Kayne (1984) and later Larson (1988), it has been assumed that the IO is in a subject position with respect to the DO. See Barss and Lasnik (1986) for discussion and Brandt (2000) for a recent claim on the subject nature of the IO.

21. Let us recall that the shared argument may be a body-part of the addressee, as in (29), repeated here: (i) $(=29)$ [...] he didn't pet my head good-bye. I will assume that this is a possibility offered by the semantics of verbs of contact. Often, these verbs give rise to the following entailment: if X verbs Y's body-part, then X verbs Y (John hit Mary's head implies John hit Mary). This means that a sentence like (i) implies the sentence without the mention of the body-part: he didn't pet me, which is a good form for the kiss goodbye construction. We could think that the acceptability of (i) derives from this implication, allowing the DP my head to count as the addressee of the interjection. Alternatively, we could build the addressee-interjection relation in the syntactic structure of the sentence itself, between the genitive DP and the interjection. I leave this technical question open for research.

22. The prepositional variant of the construction is preferably limited to inanimate DPs: (i) *She kissed goodbye to John.; (ii) We kissed goodbye to breast cancer. Though prepositional human complements are fine with a nominal kiss goodbye: (iii) no kiss goodbye to you. I leave these 
interesting facts for further investigation. I will here be concerned with the mere possibility to construe kiss in the prepositional structure. I have also left out the analysis of to as the Location preposition of Harley (2002), cited and discussed in Jung and Miyagawa (2004), and in that case, why it is the preposition subcategorized by the interjection that appears and not that of verbs of contact, at. For lack if space, I haven't investigated all the consequences of the ditransitive and prepositional alternation.

23. Kayne (1977) has noted that the embedded subject of the French causative construction is semantically constrained by the preposition a 'to'. We may think that the same holds here, and that, if to is possible here, it is because the argument is a Goal.

24. The only exceptions, considered in footnote 9, are on the following model: (i) He nodded his head yes.; (ii) He waved his hand goodbye.

25. Tell thanks is possible, contrary to the majority of formulas. This does not undermine my argument.

26. Thanks to Richard Kayne for pointing out these facts to me.

27. Goodbye bears resemblance to cognate objects, apart from the difference that, in the kiss goodbye construction, the DP headed by goodbye does not accept a genitive, whereas a cognate object does, a question I will leave open: (i) He smiled his wry smile.; (ii) *His kissed her his (sorry) goodbye.

28. This is similar to all lexical formations that get rid of argument positions, such as, among others, adjectives like interesting, which are valid without an Experiencer, even though the Experiencer is obligatory in syntax (see Haïk 2005b for evidence that this is what happens in "object pro" sentences in Romance, meaning that there is no object pro, at least in Romance).

29. Thanks to Lionel Dufaye and Jean-Yves Pollock for discussion on this subject.

30. One must distinguish between an insult and an insulting act. An insult is an interjected word or phrase, or a gesture, like giving the finger or spitting at someone, aimed at hurting and expressing ill-feeling. Kicking or slapping somebody may be insulting but these acts do not perform insults, because they are not meant to express feeling.

\section{RÉSUMÉS}

Cet article se propose d'examiner en détail une construction peu souvent étudiée, kiss goodbye ( Max kissed his mother goodbye "Max a embrassé sa mère pour lui dire au revoir »). Le grand nombre de propriétés que possède cette-ci s'explique aisément si nous l'intégrons parmi les formations à prédicat complexe qui produisent les constructions résultatives de l'anglais. Cependant, cette construction coïncide structurellement et sémantiquement avec une construction à double objet, ce qui explique son caractère hybride. Il s'agit d'une résultative qui forme une structure à double objet, et qui possède alors des propriétés sémantiques et syntaxiques des deux types de construction.

Ce travail s'inscrit dans le cadre chomskien, dont le but est de rendre compte des propriétés particulières des constructions comme dérivant de l'articulation des divers processus grammaticaux qui les produisent, ce qui signifie que cette construction devrait nous éclairer sur les résultatives en général, s'il est vrai que celle-ci est un exemplaire particulier de cette famille de constructions. 
The object of this article is to provide a thorough analysis of the little studied kiss goodbye construction (Max kissed his mother goodbye). Its great number of properties follow naturally if we integrate this construction within an articulate theory of complex-predicate formation, such as used in resultative constructions in English. However, this construction coincides structurally and semantically with a double object construction, which explains its hybrid quality. It is a resultative construction which falls into a double object frame, and hence it has properties of both types of structures and semantics.

This work belongs to the Chomskian tradition, which aims at accounting for the properties of specific constructions as the results of the interactions of the various grammatical processes that produce them, which means that it should shed light on the resultative construction itself, if it is right that the kiss goodbye construction is a particular instance of the family of resultatives.

\section{INDEX}

Keywords : kiss goodbye construction, resultative complex predicates, double object construction, performative

Mots-clés : construction kiss goodbye, prédicats complexes résultatifs, construction à double objet, performatif, interjection

\section{AUTEUR}

\section{ISABELLE HAÏK}

Université de Caen Basse-Normandie / CRISCO-EA4255 